East African Medical Journal Vol. 77 No. 11 November 2000

SUBSTANCE ABUSE IN OUTPATIENTS ATTENDING RURAL AND URBAN HEALTH CENTRES IN KENYA

C. J. Othieno, MBChB, MMed, Psych(Nbi), Lecturer, D. M. Kathuku, MBChB, MMed, Psych (Nbi), FS, Lecturer, College of Health Sciences and D. M. Ndetei, MBChB (Nbi), DPM(Lond.), MRC Psych(UK), MD(Nbi), Professor and Chairman, Department of Psychiatry, University of Nairobi, P.O. Box 19676, Nairobi.

Request for reprints to: Dr. C. J. Othieno, Department of Psychiatry, College of Health Sciences, University of Nairobi, P.O. Box 19676, Nairobi.

\title{
SUBSTANCE ABUSE IN OUTPATIENTS ATTENDING RURAL AND URBAN HEALTH CENTRES IN KENYA
}

\section{J. OTHIENO, D. M. KATHUKU and D. M. NDETEI}

\begin{abstract}
Objectives: To estimate the prevalence and pattern of substance use among patients attending primary health centres in urban and rural areas of Kenya.

Design: A descriptive cross-sectional prevalence survey.

Setting: Urban health centres of Jericho and Kenyatta University (KU) and rural health centres in Muranga district.

Subjects: One hundred and fifty adult patients (seventy eight males and seventy two females) were included in the study.

Intervention: Semi-structured questionnaires and the DSM IV diagnostic criteria were used to record the socio-demographic data and to determine substance dependence or abuse.

Results: The substances commonly used in descending order of frequency were alcohol, tobacco, khat and cannabis. Only alcohol and tobacco were extensively used. Lifetime prevalence rates of alcohol use for the two urban health centres were $54 \%$ and $62 \%$ compared to $54 \%$ for the rural health centres. For tobacco the lifetime prevalence rates were $\mathbf{3 0 \%}$ for Jericho, $28 \%$ for $\mathrm{KU}$ and $38 \%$ for Muranga. The differences between the rural and urban samples were not statistically significant. More males than females had used alcohol (average lifetime use $\mathbf{8 0 . 8 \%}$ for males compared to $30.6 \%$ for females: $p<0.05$ ) and tobacco (average lifetime use $\mathbf{5 6 . 4 \%}$ for males compared to $5.6 \%$ for females $p<0.05$ ).

Conclusion: The rates of substance abuse were generally low with the exception of alcohol and tobacco. Socio-cultural factors might be responsible for the differences noted. It is suggested that preventive measures and education should be emphasised at the primary care level.
\end{abstract}

\section{INTRODUCTION}

Abuse of substances, both licit and illicit is a cause of concern not only because of the health of the individuals concerned but also due to the socio-economic consequences and the devastating impact on close family members(1). The economic liberalisation process in Kenya has seen manufacturers of alcohol and tobacco (the main licit substances) aggressively market their products through advertisements in the mass media and various sales promotions. Moreover, due to the ease of communication and the use of Nairobi, the capital city, as a transit point by drug traffickers various illicit substances such as cocaine, heroin and mandrax find their way into the local market. It is therefore essential to monitor the situation closely by frequent prevalence surveys. General community surveys while giving the best picture are expensive to conduct. Hospital-based studies on the other hand may give higher rates than that in the general community since the patients have been filtered through referrals. The health centres being primary care settings may then be the next best alternative for assessing the situation on the ground as they are the first places of contact with the health workers.
Most of the Kenyan studies have been done in institutions like hospitals, secondary schools and colleges(2-6). These report the abuse of alcohol, tobacco, cannabis and khat to be widespread. A few of these have also reported the use of hard drugs but methodological difficulties and different diagnostic criteria used make comparisons difficult. The few community surveys done also report similar findings(7-9).

To provide baseline data for future planning, this study was designed to estimate the prevalence of substance abuse among patients attending the health centers in urban and rural areas of Kenya and to determine the types of drugs abused and any associated factors.

\section{MATERIALS AND METHODS}

Random samples of patients lining up to see the doctor or clinical officer at the primary health centres were obtained by selecting from the queue every third patient above the age of 12 years. They were interviewed using a structured questionnaire to record the socio-demographic data and to determine the types, amounts, frequency and duration of substance use. Lifetime use was elicited by the question "Have you ever used the substance," while the Diagnostic and Statistical Manual DSM IV(10) 
diagnostic criteria were used for substance dependence or abuse. The questionnaire consisted of 135 items and each interview took approximately 30 minutes to complete.

The patients from the urban centres were sampled from Jericho and Kenyatta University (KU) health centres situated respectively in the eastern part and outskirts of Nairobi city which has a population of nearly three million. The KU health centre serves the members of staff and their families as well as the students. The rural patients from Muranga district were sampled from Kandara, Maragua and Sabasaba rural health centres. These are located in a rural farming community. The data were analysed and the differences between groups tested using the Chi-square test.

\section{RESULTS}

Fifty patients from each of the health centres were included in the study. From Jericho there were 22 males, 28 females; KU 28 males, 22 females; Muranga 28 males, 22 females; giving a total of 78 males and 72 females. The mean ages were 30, 36 and 32 years for the Jericho, KU and Muranga samples respectively. The modal age group for all the three centres were in the 20-39 year age groups.

Lifetime substance use is shown in Tables 1 and 2. The average lifetime prevalence rates for alcohol use for Jericho, an urban health centre and the Muranga health centres is the same (54\%) while that of KU, the other urban area is marginally higher $(62 \%)$. Concerning tobacco, 19 (38\%) of the patients from Muranga had used tobacco compared to 15 (30\%) from Jericho and 14 (28\%) from KU. The differences were, however, not statistically significant (Table 2). Note that the males and females are merged in this table for statistical analysis. Since the male and female samples are not equal, the averages in Table 2 are different from what would be expected. For example for Jericho, 18 out of 22 males $(81.8 \%)$ and 9 out of 28 (32.1\%) females had used alcohol. Therefore 27 patients out of 50 or $54 \%$ had used alcohol.

Table 1

Lifetime substance use among the patients according to region and sex

\begin{tabular}{|c|c|c|c|c|c|c|c|c|c|c|c|c|}
\hline & \multicolumn{4}{|c|}{ Jericho } & \multicolumn{4}{|c|}{ Kenyatta University } & \multicolumn{4}{|c|}{ Muranga } \\
\hline & \multicolumn{2}{|c|}{ Male } & \multicolumn{2}{|c|}{ Female } & \multicolumn{2}{|c|}{ Male } & \multicolumn{2}{|c|}{ Female } & \multicolumn{2}{|c|}{ Male } & \multicolumn{2}{|c|}{ Female } \\
\hline & $(n=22)$ & $\%$ & $(n=28)$ & $\%$ & $(n=28)$ & $\%$ & $(n=28)$ & $\%$ & $(n=28)$ & $\%$ & $(n=22)$ & $\%$ \\
\hline Alcohol & 18 & 81.8 & 9 & 32.1 & 21 & 75.0 & 10 & 45.5 & 24 & 85.7 & 3 & 13.6 \\
\hline Tobacco & 13 & 59 & 2 & 7.4 & 12 & 42.9 & 2 & 9.1 & 19 & 67.9 & 0 & 0 \\
\hline Khat & 8 & 36.4 & 0 & 0 & 6 & 21.4 & 0 & 0 & 2 & 7.1 & 0 & 0 \\
\hline Cannabis & 4 & 8.2 & 0 & 0 & 1 & 3.6 & 0 & 0 & 3 & 10.7 & 0 & 0 \\
\hline Mandrax & 1 & 4.5 & 0 & 0 & 0 & 0 & 0 & 0 & 0 & 0 & 0 & 0 \\
\hline
\end{tabular}

Table 2

Average lifetime substance use among the patients according to region

\begin{tabular}{|c|c|c|c|c|c|c|c|c|c|}
\hline & \multicolumn{2}{|c|}{ Jericho } & \multicolumn{2}{|c|}{$\mathrm{KU}$} & \multicolumn{2}{|r|}{ Muranga } & \multirow[t]{2}{*}{ Chi-square } & \multirow[t]{2}{*}{$\mathrm{df}$} & \multirow[t]{2}{*}{$\mathrm{p}$} \\
\hline & $(\mathrm{n}=50)$ & $\%$ & $(n=50)$ & $\%$ & $(\mathrm{n}=50)$ & $\%$ & & & \\
\hline Alcohol & 27 & 54 & 31 & 62 & 27 & 54 & 3.31 & 2 & 0.194 \\
\hline Tobacco & 15 & 30 & 14 & 28 & 19 & 38 & 1.23 & 2 & 0.54 \\
\hline Khat & 8 & 16 & 6 & 12 & 2 & 4 & 4.19 & 2 & 0.123 \\
\hline Cannabis & 4 & 8 & 1 & 2 & 3 & 6 & 1.91 & 2 & 0.384 \\
\hline Mandrax & 1 & 2 & 0 & 0 & 0 & 0 & - & - & - \\
\hline
\end{tabular}

Table 3

Substance dependence among the patients

\begin{tabular}{|c|c|c|c|c|c|c|c|c|c|c|c|c|}
\hline & \multicolumn{4}{|c|}{ Jericho } & \multicolumn{4}{|c|}{ Kenyatta University } & \multicolumn{4}{|c|}{ Muranga } \\
\hline & \multicolumn{2}{|c|}{ Male } & \multicolumn{2}{|c|}{ Female } & \multicolumn{2}{|c|}{ Male } & \multicolumn{2}{|c|}{ Female } & \multicolumn{2}{|c|}{ Male } & \multicolumn{2}{|c|}{ Female } \\
\hline & $(n=22)$ & $\%$ & $(n=28)$ & $\%$ & $(n=28)$ & $\%$ & $(n=22)$ & $\%$ & $(n=28)$ & $\%$ & $(n=22)$ & $\%$ \\
\hline Alcohol & 6 & 27.3 & 2 & 7.1 & 9 & 32.1 & 3 & 13.6 & 7 & 25 & 0 & 0 \\
\hline Tobacco & 8 & 36.4 & 0 & 0 & 8 & 28.6 & 0 & 0 & 11 & 39.3 & 0 & 0 \\
\hline Khat & 0 & 0 & 0 & 0 & 0 & 0 & 0 & 0 & 0 & 0 & 0 & 0 \\
\hline Cannabis & 0 & 0 & 0 & 0 & 0 & 0 & 0 & 0 & 0 & 0 & 0 & \\
\hline Mandrax & 0 & 0 & 0 & 0 & 0 & 0 & 0 & 0 & 0 & 0 & 0 & \\
\hline
\end{tabular}


Table 4

Lifetime substance use among the patients according to sex

\begin{tabular}{|c|c|c|c|c|c|c|c|c|c|}
\hline & \multicolumn{2}{|c|}{ Male } & \multicolumn{2}{|c|}{ Female } & \multicolumn{2}{|c|}{ Total } & \multirow{2}{*}{ Chi-square } & \multirow{2}{*}{$\mathrm{df}$} & \multirow[t]{2}{*}{$\mathrm{p}$} \\
\hline & $(\mathrm{n}=78)$ & $\%$ & $(n=72)$ & $\%$ & $(\mathrm{n}=150)$ & $\%$ & & & \\
\hline Alcohol & 63 & 80.8 & 22 & 30.6 & 85 & 56.7 & 28.12 & 1 & 0.000 \\
\hline Tobacco & 44 & 56.4 & 4 & 5.6 & 48 & 32 & 43.5 & 1 & 0.000 \\
\hline Khat & 16 & 20.5 & 0 & 0 & 16 & 10.7 & 4.0 & 1 & 0.045 \\
\hline Cannabis & 8 & 10.3 & 0 & 0 & 8 & 5.3 & 8.0 & 1 & 0.004 \\
\hline Mandrax & 1 & 1.3 & 0 & 0 & 1 & 0.7 & - & - & - \\
\hline
\end{tabular}

The dependence or addiction rates are shown in Table 3. From Jericho eight patients (six males and two females) out of $50(16 \%)$ were dependent on alcohol. Corresponding figures for KU and Muranga were 24\% and 14\%. Regarding tobacco, $16 \%$ of the patients from both Jericho and KU were dependent on tobacco compared to $22 \%$ from Muranga. The general trend seen in Tables 1 and 3 is that more males than females use or abuse drugs. Since the figures were not adequate for statistical analysis, the total number of males and females from all the centres are merged in Table 4.

The males were more likely than females in general to have used the substances. They were more than twice as likely to have used alcohol and more than 10 times as likely to have used tobacco in their lifetime. No differences were noted with regard to education, marital status or socio-economic level of the patients.

\section{DISCUSSION}

It is evident that the use of hard drugs is not yet widespread among the general Kenyan population. This could be due to the fact that they are not readily available and are relatively more expensive in comparison to the other widely used drugs, alcohol and tobacco. Use of the licit substances alcohol and tobacco is quite high with about $20 \%$ of the patients dependent on them. The average prevalence rates for alcohol use obtained in this study are higher than that obtained by Yambo and Acuda in a community survey among the youth aged 10-29 years in 1983(7). Whereas $67 \%$ of the boys and $48 \%$ of the girls admitted to having used alcohol, the lifetime use of alcohol in the present study for males was $81.8 \%$ at Jericho, $75 \%$ at KU and $85.7 \%$ at Muranga. The differences could be due to the age differences between the two samples - the clinic patients being generally older. But for the females the rates are not much different being $32.1 \%$ for Jericho, $45.5 \%$ for $\mathrm{KU}$ and $13.6 \%$ for Muranga. In the youth survey, by Yambo and Acuda(7), only $11 \%$ of the male and $4.1 \%$ of the female could be considered as abusers compared to an average of $16 \%$ for Jericho, $24 \%$ for KU and $14 \%$ for Muranga.

Kiima(5) using the "Brief Mast"[Michigan Alcohol Screening Test (11)] to identify problem of drinkers at Kariobangi Health Centre in Nairobi in 1987 obtained a figure of $4.5 \%$ among 201 clinic patients screened. Among the hospital-based studies, Ndetei et al(12) found that $31.3 \%$ of in-patients at Kenyatta National Hospital were abusing alcohol. This is probably because the patients at the hospital constitute a highly selected sample through referrals. But Kigamwa(6) in a later study at the same hospital using the WHO "core" screening instrument found that only $17.1 \%$ were abusing alcohol.

The prevalence rates of alcohol use in the present study are also higher compared to those of a recent survey in Kajiado District in Kenya where 54\% and 34\% of settled and unsettled Maasai respectively admitted to having used alcohol(9). Among these, only three per cent could be considered to be abusing alcohol. The rate of abuse is, however, comparable to that of $3.5 \%$ for alcohol abuse and $7.2 \%$ for alcohol dependence obtained from a recent study on general practice patients in Germany(13). The high rates for the general Kenyan population could be due to the social acceptability of the substances (alcohol and tobacco), easy availability and the result of sales promotions through uncontrolled advertisements.

It is postulated that socio-cultural factors can help to keep substance abuse in check. For example, in most traditional African societies, women who smoke or drink in public are shunned. This could explain the low prevalence of substance use and abuse among women compared to men. As lifestyles change due to urbanisation one would expect a corresponding increase in substance use. Indeed only $13.6 \%$ of the women from Muranga had ever used alcohol compared to $45.5 \%$ and $32.1 \%$ from the $\mathrm{KU}$ and Jericho samples, respectively. A similar trend is seen in tobacco use where no woman from Muranga reported having smoked whereas two each from the KU and Jericho health centers had smoked. In the Kajiado survey, substance use among the unsettled Maasai who traditional lives in remote places was generally lower than that among the settled ones who were more urbanised. For example, lifetime tobacco use was $14 \%$ among the settled and two per cent among the unsettled Maasai. Only one per cent and $1.7 \%(\mathrm{n}=170)$ of the total sample admitted to using khat and cannabis respectively. All were from settled areas. A recent Zimbabwe study among secondary school students also found that a global (western) cultural orientation was significantly associated with increased use of cannabis and inhalants among the youth(14). Similar socio-cultural factors could also be keeping the use of hard drugs, for example heroin and cocaine, in check in most 
parts of Kenya. Where there is more global influence due to tourism, for example, one would expect higher rates for these hard drugs(15). Few studies have, however, addressed these aspects.

Harmful effects of tobacco include heart and lung diseases, while alcohol abuse may lead to severe social, medical and psychological problems. Cannabis abuse may induce a wide range of psychological symptoms ranging from anxiety to psychotic states(16). The social and medical problems, including psychotic states, associated with khat have also been described $(17,18)$. It is therefore desirable that the use of these substances be curtailed. While prevention would be the best strategy in combating substance abuse, identification and treatment of established cases is equally important(19). It is not known what proportion of patients in this study would have been identified by the health workers as dependent on alcohol or tobacco but it is likely that many would have been missed. It is therefore recommended that public awareness on harmful effects of drugs be enhanced and screening done routinely on all patients to pick out the cases.

Further community surveys are needed to assess the knowledge and attitude of the community members on substance abuse. Periodic surveys to assess the prevalence rates are also necessary to evaluate and adjust any preventive or rehabilitative measures in place.

\section{ACKNOWLEDGEMENTS}

The Chief Medical Officer, Kenyatta University College, the clinical officers at Jericho and Muranga Health Centres, Mr. Osoti and Mr. Ngoitsi for assisting in the data collection.

\section{REFERENCES}

1. Acuda, S W. Drug dependence: Health and socio-economic consequences. East Afr. Med. J. 1988; 65:643-652.

2. Dhadphale, M., arap Mengech, H. N.K., Syme, D. and Acuda, S. W. Drug abuse among secondary school students in Kenya: a preliminary survey. East Afr. Med. J. 1982; 59:152-156.

3. Kuria, M.W., Drug abuse among urban as compared to rural secondary school students in Kenya. A short communication. East Afr. Med. J. 1996; 73:339.
4. Amayo, G N. Alcohol use among Kenyan students and teachers in secondary schools and colleges. Healthline 1998; 2:30.

5. Kiima, D. T. M Psychiatric morbidity among patients attending a Primary Health Care Centre in a socially deprived community. Master of Medicine Thesis. University of Nairobi. 1987.

6. Kigamwa, P. A. Psychiatric morbidity among medical in-patients at Kenyatta National Hospital. Master of Medicine Thesis. University of Nairobi. 1988.

7. Yambo, M. and Acuda S. W. Epidemiology of drug use and abuse. Final report of a pilot study in Nairobi city and Kyaume sublocation Kenya. University of Nairobi. Nairobi. Dec. 1983.

8. Bittah, O., Owola J. A. and Oduor P. A study of alcoholism in a rural setting in Kenya. East Afr. Med. J. 1979; 56: 665-670.

9. Abu-Saad, I. The Influence of Settlement on substance abuse among nomadic populations in Israel and Kenya. Final report. Center for Bedouin Studies and Development. Ben-Gurion University of the Negev. 1998.

10. American Psychiatric Association: Diagnostic and Statistical manual of mental disorders, edn 4. American Psychiatric Association, Washington, 1994.

11. Selzer, M.L. The Michigan Alcoholism Screening Test. The Quest for a new diagnostic instrument.Amer. J. Psychiat. 1971; 127:1653 - 58.

12. Ndetei, D. M.. Kiptoon, P., Odhiambo, K. The prevalence of alcoholism among patients at Kenyatta National hospital. Medicom. 1983; 5:41-42.

13. Hill, A., Rumpf, H. J, Hapke U., Driessen, M. and John U. Prevalence of alcohol dependence and abuse in general practice. Alcohol: Clin. Exp. Res. 1998; 22:935-940.

14. Eide, A H. and Acuda S. W. Cultural orientation and use of cannabis and inhalants among secondary school children in Zimbabwe. Soc. Sci. Med. 1997; 45:1241-1249.

15. Beckerleg, S., Telfer, M. and Sizi, A. K. Private struggles, public support: Rehabilitating heroin users in Kenya. Drugs: Educ. Prev. Pol. 1996; 3:159-169.

16. Thomas, H. A community survey of adverse effects of cannabis use. Drugs Alcoh. Dep. 1996; 42: 201-207.

17. Balint G. A., Ghebrekidan, H. and Balint E. E. Catha edulis, an international socio-medical problem with considerable pharmacological complications. East Afr. Med. J. 1991; 68: 555561 .

18. Dhadphale, M., arap Mengech, H. N. K. and Chege, S. W. Miraa (catha edulis) as a cause of psychosis. East Afr. Med. J. 1981, 58:130-135.

19. Crits-Christoph, P. and Siqueland, L. Psychosocial treatment of drug abuse: selected review and recommendations for national health care. Arch. Gen. Psychiat. 1996; 53:749-756 